\title{
A Comparative Study of Learning Anxiety between Rural Left-behind Children and Non-left-behind Children
}

\author{
Xiaofang Li \\ School of Foreign Languages, Yan'an University, Shaanxi Province, China \\ 1765229450@QQ.com
}

\begin{abstract}
Keywords: Learning anxiety; Survey; Left-behind children; Non- left-behind children
\end{abstract}
\begin{abstract}
Objective: to investigate the learning anxiety level of rural left-behind children and non-left-behind children. Method: Adopted the anxiety subscales of "mental health diagnostic test" (MHT), this research has made an investigation on 363 rural left-behind children and non left-behind children. Results: (1) According to the survey, in the aspect of learning anxiety, the degree of leaning anxiety of left-behind children is much serious than that of non- left-behind children, and they two have significant difference $(\mathrm{t}=2.131, \mathrm{P}<0.05)$. Left-behind children need special guidance. (2) For left-behind children of different genders, there are significant differences between male and female students $((\mathrm{t}=1.991, \mathrm{P}<0.05)$, and girls need special guidance. There was no significant difference between genders for non-left-behind children $(\mathrm{t}=0.957, \mathrm{P}>0.05)$. Conclusion: in the future teaching, attention should be paid to the left-behind children' learning anxiety, especially the correct guidance to the female left-behind children.
\end{abstract}

\section{The Introduction}

Due to the differences between urban and rural development in our country, the income engaged in farming is far lower than that of migrant workers in cities, in this situation, "urban jobs and family separation" become the rational choice for migrant workers [1]. The transfer of surplus labor force from rural to urban, one way is the surplus labor force from the underdeveloped countryside transfer to the rural developed urban areas, another way is the industrial transfer, geographically speaking, which is the process of massive migration of labor force from rural area to the city[2]. Therefore, plenty of Left-behind children (LBC) have appeared. LBC refer to the children who can't live together with both parents and either parent when their parents are moved to cities for work, and their children remain in their registered permanent residence [3]. According to the "2012 statistics bulletin of the national education career" of ministry of education on August 17, 2013, the national rural left-behind children covers almost one sixth in the compulsory education stage student [4]. According to the China's sixth census data in 2010 , there are 278.91 million children aged from 0 to 17 , in which there are 69.7275 million left-behind children, and the national rural left-behind children is 61.0255 million, which is an increase of 2.42 million national rural left-behind children compared with the $1 \%$ sampling survey in 2005 [5].In addition, according to the national women's federation statistics in 2015, the percentage of LBC accounts for $38 \%$ from 0 to 5 years old, 32\% from 6 to 11 years old, $16 \%$ from 12 to 14 years old, $13 \%$ from 15 to 17 years old respectively [6].As for left-behind children, there are plenty of studies in domestic demography, pedagogy, psychology, sociology and so on. At present, the number of domestic studies is increasing; the research angle is diversified, focused mainly on the difference between left-behind children and non-left-behind children. Most of the conclusion of domestic research is similar to that of foreign researches. From the research conclusion, negative conclusions are common [7]. The main problems of LBC are summarized mental health problems, personality development issues, emotional problems, behavioral problems, social and school adaptation issues, interpersonal problems, academic and moral questions, etc [8]. Therefore, the mental health level of left-behind children is not optimistic, and mental health is influenced by personality and social support. Social support can improve personality traits and improve mental health [9].This research focus on the learning anxiety of 
left-behind children, to help teachers, parents and students understand the existing problems, and then guide them from the cognitive and behavioral level to improve their level of mental health.

\section{Research design \\ Research Questions}

Is there any obvious learning anxiety among left-behind children and non-left-behind children (NLBC)? Is there a significant difference between the two?

Is there any significant difference in sex on the degree of anxiety for left-behind children and non-left-behind children?

\section{Research subjects}

In this study, four primary schools were selected as the study subjects in different counties in northern Shaanxi, on one hand, the four schools are far away from the town, and there are more left-behind children there. On the other hand, the situation of these four schools is particularly common in northern Shaanxi, therefore it can stand for the common social phenomenon. The survey was carried out by students from grades three to grade six, because it was estimated that students in grade one and two have some difficulty in understanding the questionnaire. The number of participants in the four schools was 164, 91, 98 and 48. A total of 401 students were surveyed, with 363 valid questionnaires (185 for left-behind children and 178 for non-left-behind children, 199 male and 164 female).

\section{Research Instrument}

This study adopts the anxiety subscale in the Mental Health Diagnostic Test (MHT) standardized by middle school students in China. MHT is edited by Professor Zhou Bucheng and other psychological science researchers of East China Normal University according to "anxiety tendency diagnostic test" by Japan's suzuki qing et al, which include two parts (the subjects and behavior of anxiety) and 8 subscales. The instrument is applied to primary and secondary school students. The questionnaire of the study consists of 15 items, each of which is "consistent" and "inconsistent", If "consistent" is chose, the subject get 1 point, if "inconsistent" is chose, the subject gets 0 point. If the score of the whole scale is higher than 8 points or more, that is to say that the examinee has a psychological fear to learning and they are unable to study normally and are concerned much about test scores. Such students should accept specific guidance plans [10].

After the survey of questionnaire, the nine left-behind children, whose either father or mother or both have been working away from their homes, have been interviewed respectively.

\section{Research Results}

\section{The learning anxiety of left-behind children and non-left-behind children}

As the survey reveals that learning anxiety level of left-behind children is 8.353 , the standard deviation is 2.962. According to scoring rules and results interpretation of "the mental health test" (MHT), it means that the subjects have a psychological fear to test and they are unable to study normally and is concerned much about test scores. Such students need special guidance. Compared with the left-behind children, the non-left-behind children learning anxiety level is weaker, the mean value is 7.641, the standard deviation of 2.852, which shows that the exam pressure on LBC students is stronger than that of NLBC in general. In order to test whether there is a significant difference between LBC students and NLBC the independent sample $t$ test has been made and $t$ value is 2.131 , the Sig. on both sides is .046 which is less than .05, that is to say that the level of learning anxiety for LBC has significant difference with that of NLBC (see table 3.1).

Table 1 Study anxiety differences between LBC and NLBC

\begin{tabular}{|c|c|c|c|c|}
\hline LBC(185) & NLBC (178) & & $\mathbf{t}$ & Sig. \\
\hline $\mathrm{M} \quad \mathrm{SD}$ & $\mathrm{M} \quad \mathrm{SD}$ & Difference & & \\
\hline $\begin{array}{l}8.353 \\
2.962\end{array}$ & $\begin{array}{l}7.641 \\
2.852\end{array}$ & .712 & 2.131 & .046 \\
\hline
\end{tabular}


Situation of left-behind children are divided into three groups: Group A refers to LBC whose father have been out to work for a long time, Group B refers to LBC whose mother have been out to work for a long time, Group $\mathrm{C}$ refers to $\mathrm{LBC}$ whose mother and father have been out to work for a long time. As for the three groups, the highest level of anxiety is group A and the mean value is 8.672, the second one is group $\mathrm{B}$ the mean of group $\mathrm{C}$ the weakest, whose mean value is 7.562 , which is below the mean of learning anxiety levels for NLBC (see table2).

Table 2 The descriptive statistics of three groups

\begin{tabular}{|c|c|c|}
\hline $\begin{array}{l}\text { Group } \\
\text { A( } 127)\end{array}$ & $\begin{array}{c}\text { Group B } \\
\text { (20) }\end{array}$ & $\begin{array}{l}\text { Group } \\
\text { C(38) }\end{array}$ \\
\hline M SD & $\mathrm{M} \quad \mathrm{SD}$ & $\mathrm{M} \quad \mathrm{SD}$ \\
\hline $8.672 \quad .961$ & $\begin{array}{l}7.803 \\
3.134\end{array}$ & $7.562 \quad .685$ \\
\hline
\end{tabular}

According to the single factor ANOVA and multiple comparative analysis, there is no significant difference in the learning anxiety of the left-behind children between Group A and Group B with the value of Sig .212, greater than 0.05. there is significant difference in the learning anxiety of the left-behind children between Group A and Group C, with the value of Sig .037, less than 0.05 (see table $3.3)$.

Table 3 Multiple comparative analysis of different groups

\begin{tabular}{r|c|c|ll}
\hline & Mean difference & Sig. & \multicolumn{2}{|c}{$\begin{array}{c}\text { 95\% confidence interval of the difference } \\
\text { Lower }\end{array}$} \\
\hline A B & .872 & .212 & -.491 & Upper \\
C & 1.121 & $.037^{*}$ & .062 & 2.232 \\
\hline
\end{tabular}

Note* the significance level is 0.05

$\mathrm{A}=$ Group A,B= Group B, C= Group C

In order to further know the reason of the different groups of left-behind children in learning anxiety, three students in each group were interviewed. The students of Group A said that their mothers often checked their learning and they were afraid of their dad if they didn't work hard. The students of Group B said that their fathers were often busy and they seldom strictly checked their learning without their mother's supervision. As for the LBC of Group C, they said that the phone call was different from the behavior, even if the result of exam was not good, they wouldn't scold seriously, so it didn't matter.

\section{Learning Anxiety of Different Gender for $\mathrm{LBC}$ and NLBC}

In order to know whether there is significant difference between boys and girls for left-behind children, the independent sample t-test is made. According to the test result, $t$ value is 1.991 and the Sig. (double side) value is. 047, which is less than .05, that is to say that there is significant difference between boys and girls in learning anxiety; The mean of the boys is obviously lower than that of the girls, no more than eight points, who need no special instructions. The mean of the girls was 8.803 . the girls need specific guidance plans.

Table 4 The Learning anxiety of different gender for LBC

\begin{tabular}{l|ll|l|l|l}
\hline male(97) & \multicolumn{2}{|l|}{$\begin{array}{l}\text { female(88) } \\
\text { M SD }\end{array}$} & $\begin{array}{l}\text { Mean } \\
\text { difference }\end{array}$ & t & Sig. \\
$\begin{array}{l}\text { M SD } \\
7.941\end{array}$ & 8.803 & .961 & .862 & 1.991 & .047 \\
2.90 & & & & & \\
\hline
\end{tabular}


For the non-left-behind children, the boys' learning anxiety level is lower than the girls, the scores of both are no more than eight points, and independent sample t-test results shows that the Sig. (double side) values is greater than .05 , which mean that there is no significant difference between boys and girls. (see table 3.5).

Table 5 The learning anxiety of different gender for NLBC

\begin{tabular}{|c|c|c|c|c|}
\hline male(102) & female(76) & Mean & $\mathbf{t}$ & Sig. \\
\hline M SD & M SD & difference & & \\
\hline 7.321 .683 & $\begin{array}{l}7.992 \\
3.014\end{array}$ & .671 & .957 & .122 \\
\hline
\end{tabular}

\section{Conclusion}

Through the investigation, it found that the learning anxiety level of LBC is higher than that of non left-behind children, there is significant difference between them. The learning anxiety level of LBC is higher than eight points, and they need special instruction, especially LBC whose father have been away to work for a long time. For left-behind children of different genders, there is significant difference between male and female students, and the degree of female is higher and they need special guidance. For non-left-behind children of different genders, there is no significant difference between male and female students. No special guidance is required. Therefore, in the future teaching, schools, parents should pay attention to the left-behind children learning and learning anxiety, especially the female left-behind children need to be guided correctly.

\section{References}

[1] Ren Yuan, Left-behind Children and Family-supportive Social Policies during Urbanization [J]Nanjing Journal of Social Sciences,2015,8:73-75.

[2] Ye Jingzhong, James. Murray, Focusing on Left-behind Children-- the Influence of Migrant Workers on Left-behind Children in Rural Areas in Central and Western China[M]Beijing: Social Science and Literature Press, 2005: 42.

[3] Duan Chengrong, Yang Ke, A Study on the Status of Left-behind Children in Rural China [J] Population Research, 2008,32(3):15-25.

[4] The ministry of education, 2012 National Education Career Development Statistics Bulletin [N] China education, 2013-8-17 (2).

[5] Duan Chengrong et al., the Basic Situation of the Survival and Development of Left-behind Children in Rural China - Based on the Analysis of the Sixth Census Data [J] Population Journal, 2013,(3):40.

[6] Li Jing al. Review of Chinese Left-behind Children's Development [J] Social Sciences Perspectives in Higher Education, 2017,1:28.

[7] Wan Ming Gang, MAO Rui A number of Problems Existing in the Study of Left-behind Children in China [J] Journal of northwest normal university. 2010,01:

[8] Bjorn Albin, al. Mental Health in the Left-behind Children in the Fujian Province of China[J]Journal of Public Mental Health,2013,12(1):23-30.

[9] Yang Tonghua al. Left-behind Childrren's Mental Health: the Influences of Personality Traits and Social Support [J] China Journal of Health Psychology,2016,Vol24(2):285.

[10] Song Zhuanmao, Chen Wei. Mental Health Measurement [M] Guangzhou: Jinan University Press, 2001, 